\title{
La intriga en la Samia de Menandro el error y la ironia
}

\author{
PATRICIA MABEL SACONI \\ Facultad de Filosofia y Letras \\ Universidad de Buenos Aires
}

\begin{abstract}
RESUMO: A intriga da Sâmia de Menandro, visto que não existe um sucesso concreto que impossibilite a realização da boda, estrutura-se em função dos obstáculos secundários que retardam o desenlace final. A análise da relação entre os personagens permite identificar a estrutura da composição e determinar a intenção da criação poética, que se enquadra no tema do conhecimento da verdade.
\end{abstract}

PALAVRAS-CHAVE: Menandro, Sâmia, comédia, literatura grega, Grécia.

La Samia de Menandro presenta un desarrollo escénico particular ya que en el comienzo de la obra no existe obstáculo concreto que impida la realización de la boda de la pareja de jóvenes ${ }^{1}$. La intriga se estructura en función de los obstáculos secundarios y de este modo se retarda la resolución hasta el final de la comedia.

El poeta conforma el universo de la acción frente a un espectador que conoce, a partir del prólogo de Mosquión, cómo se han desarrollado los hechos pasados, cuáles son los sentimientos del mismo Mosquión hacia Plangón y en parte - dado que el texto es fragmentario - el grado de participación de la Samia para mantener en secreto la identidad de los padres del niño hasta que se celebre la boda.

El personaje de Mosquión presenta en el prólogo (vv. 1 - 57) la estructuración orgánica de hechos concretos de existencia real o ideal, que funciona como referente de verdad: macrocosmos real-1. Al mismo tiempo, Mosquión establecerá, a lo largo de la obra, un universo paralelo, falaz, en el cual participarán todos los otros personajes.

Cada personaje se relacionará con los demás dentro de microcosmos particulares, considerándose como microcosmos a la unidad estructural cuyos espacios funcionales están integrados:

A- por lo que los personajes saben o creen saber sobre la realidad

B-por el referente de sus discursos

C- por las hipótesis que los personajes construyen a partir de la combinación de lo receptado con su propio saber.

Los microcosmos, de acuerdo con los datos del prólogo, constituirán el universo falaz y tendrán apariencia de verdad para los personajes que se sitúen en ellos. 
En el presente trabajo se realizará el análisis de los microscosmos en forma individual y de las conexiones entre los mismos para definir que función tiene la relación que se estabelezca con respecti al desarrollo de la intriga y, a partir de este análisis, definir la intención de la creación poética.

La enunciación de los hechos del prólogo es verdadera en tanto su referente son sucessos determinados, con existencia concreta, ya en el pasado inmediato, ya en un pasado anterior. Estos hechos - que comprenden por un lado los acontecimientos propiamente dichos (vv. 7-8, 13-22, 35-52) y, por otro, las reflexiones de Mosquión (vv. 3, 22, 23, 24, 27, 53) - coforman el macrocosmos $1^{0}$, como un eje con realidad objetiva para la confrontación de los constituyentes de los microcosmos particulares.

Los primeros versos del prólogo contienen el problema que desencadena la peripecia posterior: hemárteka (v. 3). La descripción y las acotaciones subjetivas (vv. 39, 47-48) connotan la hamartía como un error involuntario con inesperadas consecuencias.

El encuentro de Crysis, Mosquión y Pármeno en el Acto I establece el microcosmos A. A pesar del caracter fragmentario del texto está explicitado el conocimiento de los tres personajes acerca de los elementos del macrocosmos 12:

- existencia de un niño recién nacido

- paternidad del niño (hijo de Mosquión)

- maternidad del niño (hijo de Plangón) - voluntad de Mosquión para concretar la boda con Plangón

- promesa de Mosquión a la madre de la joven en cuanto a realizar la boda.

Entre los tres personajes acuerdan que Crysis, la Samia, alimentará al niño hasta que Mosquión comunique a su padre adoptivo, Demeas, lo sucedido y se realice la boda. La Samia y Pármeno saben que Mosquión conoce la relación amorosa de Demeas con Crysis, relación que Demeas ha ocultado. Saben además, que debido a la vergüenza Mosquión demorará en hablar con su padre.

También en el Acto I se establece el microcosmos B con la aparición en escena de Demeas y Nicérato, quienes, aunque desconocen la relación entre sus hijos, han planeado desposarlos. Este acuerdo no interfiere con los constituyentes del microcosmos A.

Con el encuentro entre Mosquión y Demeas en el Acto II se establece el microcosmos C. A partir de aqui el espectador puede inferir la inmediata resolución del problema de Mosquión en función del plan de su padre; pero, justamente en este punto, comienza el enredo provocado por el manejo inadecuado de la información que Mosquión transmite. Demeas revela a Mosquión que tiene una esposa, la Samia, que ha tenido un hijo durante su ausencia y que por esto la echará de la casa: láthrióls tils hy[ós], hos éoike, gégone moi (v. 132) ${ }^{2}$. Mosquión finge desconocer la existencia de tal esposa, no averigua cómo se ha enterado su padre de la maternidad, defiende la condición de "hijo bastardo" y finalmente, comunica a Demeas que está enamorado y desea casarse. Esta es la primera actitud elusiva operada por un personaje que participa del microcosmos A: Mosquión ha perdido una oportunidad para aclarar el asunto y su silencio funciona como un implícito sobre el cual Demeas construirá su pensamiento sobre la realidad.

En el Acto III se establece el microcosmos D a partir de la experiencia sensible de Demeas, con cuyo discurso comunica que a hora sabe que el niño es de Mosquión y, aunque no explicita que lo ha escuchado, repite las palabras de la antigua nodriza de Mosquión al niño: nŷn d'epèi / paidíon ekéinou gégone (vv. 
247-248). Demeas confirma también que la Samia es la madre, pues la ve amamantando al niño.

El escuchar y el ver legitiman para si mismo el conocimiento que Demeas tiene sobre la realidad y de este modo se establece el universo falaz paralelo al macrocosmos I. Los constituyentes de ese universo falaz son lo único que Demeas acepta como verdadero cuando ha confirmado su saber anterior a partir de la confrontación con lo que ha percibido. Adquiere, además, un saber certero: la paternidad de Mosquión. El universo, constituido por exterioricidades engañosas, es falaz en tanto ostenta una cualidad que no tiene, la apariencia de verdad.

Con el enfrentamiento de los microcosmos A y D (vv. 295-324) se establece la situación comunicativa desencadenada a partir de la interdiscursividad que opera como supuesto entre los interlocutores ${ }^{3}$ : Demeas "sabe" que Pármeno "sabe", Pármeno no sabe "cuánto" sabe Demeas. De los dos elementos supuestamente conocidos por Demeas, la paternidad y la maternidad del niño, Pármeno le confirma el primero. Esta es la segunda actitud elusiva operada por un personaje que participa del microcosmos A: Pármeno ha perdido una oportunidad para develar la verdad frente a Demeas. Para Demeas, la legitimidad de su saber está garantizada por un componente psicosocial: la condición de esclavo de Pármeno que lo obliga a ser veraz con su amo.

El universo falaz se completa con la interpretación de Demeas sobre la boda de su hijo: a la luz de "todo lo que sabe" infiere que Mosquión se casaria con Plangón para escapar de la Samia.

Con el encuentro de Demeas y Crysis (vv. 369-382) se establece el microcosmos E. Tiene lugar, entonces, una situación monolocutiva en el plano semántico, articulada como diálogo en la estructura superficial, donde Demeas exhorta a la Samia para que abandone la casa junto con el niño. Justifica este deseo con las razones acerca de la conducta de la mujer. Incluye el discurso de Demeas:

1- la apelación reforzada por una invocación calificativa peyorativa que retoma la reflexión de Crysis sobre si misma (vv. 369-370).

2- los enunciados afirmativos que respaldan la orden (vv. 371 ss.)

El discurso de la Samia está constituido por ocho sintagmas interrogativos, ninguno de los cuales recibe respuesta satisfactoria, lo que demuestra que no logra ser reconocida como hablante por parte del receptor (Demeas). La Samia no sabe que Demeas cree que el niño "es"de ella y de Mosquión, pero en tanto no aclara nada respecto de este punto se opera la tercera actitud elusiva por parte de un personaje que participa del microcosmos $A$, perdiéndose otra oportunidad para solucionar el problema.

Demeas ha quedado aislado en el universo falaz por la serie de actitudes elusivas operadas por quienes, paradójicamente, cooperarian para resolver de manera satisfactoria el problema de Mosquión frente a su padre adoptivo.

El Acto III finaliza con el establecimiento del microcosmos F por el encuentro de Crysis y Nicératos. Nicératos, que pertenece a una clase social inferior a la de Demeas, es un personaje psicologicamente simple lo que justifica que no interpretará suspicazmente lo que percibe. Sabe que la Samia recogió un niño, no comprende la actitud de Demeas y, de acuerdo a cómo lo ve actuar, dice acerca de Demeas lo que más se ajusta a la definición de su conducta: paúseth'hoútos apomaneis (v. 419).

En el Acto IV se establece el microcosmos $\mathbf{G}$ en tanto se reúnen Nicératos, Demeas y Mosquión con el siguiente resultado: por encontrarse presente Nicératos, 
Mosquión no aclara quién es la madre del niño aunque acepta su paternidad, perdiemdo otra oportunidad de develar ia verdad a su padre. Esto refuerza la convicción de Demeas, ubicado en el universo falaz, de que él "sabe todo" (v. 466).

Al retirarse Nicératos de la escena se establece el microcosmos $\mathrm{H}$ : Mosquión comunica a su padre la forma en que se produjeron los acontecimientos y a partir de esto (v. 521) Demeas comienza a participar del macrocosmos $1^{2}$, quedando anulado el universo falaz cuyo soporte era la perspectiva de Demeas.

El establecimiento del microcosmos I se produce con el encuentro entre Demeas y Nicératos, quien desea vengar la deshonra de su hija. El discurso de Demeas contiene una alusión mítica (vv. 589-591), referida a la posible participación divina en el nacimiento del niño cuya finalidad es tranquilizar a Nicératos. Si bien Nicératos sabe que el padre es Mosquión, simula haberse persuadido y así acelerar la concreción de la boda.

Los personajes quedan asimilados al macrocosmos I una vez que ha desaparecido el obstáculo retardador del desenlace de la acción, es decir, el conjunto de estados mentales y emocionales de los personajes: vergüenza de Mosquión (microscosmos A, C, G), temor del amo en Pármeno (microcosmos A + D), desesperación y confusión de Crysis (microcosmos $\mathrm{E}$ y F), ofuscación y persistencia en el error de Demeas (microcosmos C, D, E, G), y cólera de Nicératos (microcosmos I).

El Acto V comienza con otro monólogo de Mosquión (vv. 616-640), de tono solemne, sobre el amor, la honra y el castigo a la desconfianza de su padre, temas que se relacionan con el desarrollo posterior de la acción, donde el motivo del miles gloriosus funciona como instancia desencadenante de otro engaño. El monólogo tiene doble función en tanto presenta el raconto de lo sucedido hasta el momento y establece las pautas de una nueva intriga que involucrará a Pármeno, Nicérato y Demeas. El discurso de estos personajes - que actúan creyendo en la intención de Mosquión - manifestará las suposiciones acerca de las consecuencias de esta intención (partir como soldado) para Plangón, que no podría casarse.

El monólogo comunica la finalidad del engaño producido voluntariamente: ei methèn áll, autón phobêsai boúlomai (635). Este monólogo presenta la estructuración orgánica de los hechos que funciona como referente de verdad para esta nueva secuencia: el macrocosmos real-2 ${ }^{2}$. Sucesivamente se establecen los microcosmos $\mathrm{J}$ y K, el primero cuando Pármeno, Nicérato y Demeas creen que Mosquión desea partir $e$ intentan persuadirlo para que no lo haga (vv. 657-694); el segundo cuando Demeas y Nicérato creen haberlo persuadido y éste se dispone a casarse (vv. 695 ss.).

Los personajes engañados no podrán participar del macrocosmos- $2^{2}$ pues ninguno sabrá que ha presenciado una farsa urdida por Mosquión.

Existen en la obra dos monólogos (Acto I y Acto IV), pronunciados por Mosquión, cuyo referente está constituido por circunstancias objetivas de existencia real o ideal. Los hechos a los que se hace referencia serán punto de partida para la reacción de los demás personajes. A partir de la emisión de los monólogos Mosquión se presenta como el "único que saben y es el, en última instancia, el personaje de quien depende la develación de la verdad. Este carácter confiere a Mosquión una jerarquia superior respecto de los otros personajes, que dependen "del que sabe" para conocer la "verdad".

En función de la relación de las comedias de Menandro con las tragedias de Eurípides ${ }^{4}$, es posible comparar los dos prólogos con aquellos pronunciados por personajes de naturaleza humana o divina en esas tragedias. Por su parte, Mosquión, quien pronuncia los monólogos, es presentado como un joven que 
comete errores, se acobarda frente a las circunstancias adversas y engaña a su padre. Estas características del personaje en relación con su función de "develador" constituyen el eje de la intención irónica en la obra.

En segundo lugar, es posible identificar una relación en cuanto a la organización formal entre la Samia y las tragedias euripideas, donde se presentan intrigas sucesivas 5 . En la Samia se presentan dos intrigas sucesivas, la primera, producida por el error involuntario de Mosquión, con consecuencias no deseadas por él y que se resuelve en el plano de la verdad; la segunda, producida por un engaño voluntario, con consecuencias deseadas por Mosquión y que se resuelve en el plano de la apariencia. En ambos casos el agente desencadenante de la intriga es el joven Mosquión quien, a diferencia de los otros, tiene un atributo que lo acerca al plano divino: el poder sobre verdad y sobre la apariencia.

Respecto del engaño, la confrontación de este personaje con los de las tragedias de Eurípides, de naturaleza humana o divina, y la presencia de la alusión mítica evidencian el elemento irónico de esta comedia ${ }^{6}$. El error en el plano de los personajes, cuya consecuencia es el retraso del desenlace, es el vehículo mediante el cual se hace presente la ironía.

El error se manifesta, con su caracter de involuntario, en todas las instancias de la obra a través de los personajes: Mosquión ha engendrado un niño por encontrarse donde no estaba permitido (Prólogo); Demeas comete un error en la interpretación de aquello que ha percibido (Acto II - III); Nicérato comete un error por desconocimiento al considerar que la Samia es la madre del niño (Acto III); hay un error de omisión de la verdad en Mosquión (Acto II - IV), Pármeno (Acto III) y Crysis (Acto III) que refuerza el error de Demeas; voluntariamente Mosquión inducirá a otros personajes al error de creer verdadera su intención de partir como soldado (Acto V).

Los diferentes errores constituyen el andamiaje para la estructuración de las intrigas donde Mosquión - también involucrado en el sistema de errores - es vehículo para la expresión de la ironía.

El tema de la obra es el problema del conocimiento. Menandro postula en la Samia la existencia de un limite para la percepción de la verdad y la apariencia. Con evidente influencia del poeta trágico en la forma de composición, cuestiona para el hombre, para su público, -por la resolución de la última intriga- la capacidad de reconocer si es posible permanecer en la esfera de la verdad o de.la apariencia.

\section{Notas}

1- Acerca de la falta de obstáculo inicial en esta comedia cf. KLULS.

2- Cf. MENANDRO, Commodie, nota $\mathrm{n}^{2} 26$, a los w. 129-130, donde se interpreta que Crysis intenta convertirse en esposa legitima de Demeas por no haber expuesto al niño. 3- Interdiscursividad: este concepto es definido por CHARAUDEAU, Patrik en el seminario intensivo Análisis del discurso. Un modelo de comunicación, dictado en la Facultad de Filosofia y Letras-UBA (1 y 2 de septiembre de 1988) como "lo común entre los interlocutores desde el punto de vista del saber; entre los partenaires están las representaciones del mundo y para que se dé la comunicación es necesario buscar las representaciones mínimas compartidas -supuestamente compartidas- en cuanto al saber". 
4- Acerca de la relación entre la obra de Menandro con las tragedias de Eurípides cf. ARNOTT; DWORAKI; POOLE; POST.

5- De las diecinueve tragedias existentes, por lo menos ocho presentan intrigas sucesivas: Alcestes vv. 1 - 836 y vv. 837 - 1163; Ion vv. 1 - 675 y vv. 676 - 1622; Hipólito vv. 1 - 789 y vv. 790 - 1466; Andrómaca vv. 1 - 765 y vv. 766 - 1288; Hécuba vv. 1 - 655 y vv. 656 - 1295; Electra vv. 1 - 581 y vv. 582 - 1359; La locura de Heracles wv. 1 - 700 y vv. 701 - 1429; Las Fenicias vv. 1 - 1018, vv. 1019 - 1479 y vv. 1480 - 1766.

6- De las diecinueve tragedias existentes, por lo menos doce presentan personajes que realizan engaños con fines determinados: El Cíclope: Odiseo (w. 441 - 468); Medea: Medea (w. 364 - 375 y vv. 764 - 789); Hipólito: Fedra (wv. 855 - 890); Ion: Creusa (w. 1029 - 1038); Hécuba: Hécuba (w. 952 - 1036); Ifigenia en Táuride: Ifigénia (w. 1029 1051); Electra: Electra (vv. 1124 - 1146); Orestes: Orestes y P1lades (vv. 1105 - 1130); Las Fenicias: Meneceo (vv. 985 - 1018); Ifigenia en Aulide: Agamenón (vv. 87 - 114); Helena : Helena (vv. 1049 - 1082); Las Bacantes: Dionisos (w. 848 - 861). Por lo menos en cinco tragedias existen personajes que al ocultar información retardan el desenlace de la intriga: Admeto en Alcestes, Creusa y la sacerdotisa de Apolo en Ion, la nodriza en Hipólito, Ifigenia y Orestes en Ifigenia en Táuride, Orestes en Electra.

\section{Referencias Bibliográficas}

ARNOTT, W. C. From Aristophanes to Menander. Greece and Rome. Oxford, 19, n.1, p. 65-80, 1972.

DWORAKI, S. "Iyon" Eurypidesa a Komodie Menandra. Symbolae Philologorum Posnanensium. Posnán, 6, p. 21-31, 1983.

EURIPIDES. PAGE, T.E.; CAPPS, E.; ROUSE, W. H. D. (eds.). London: Heineman, 1930.

KLULS, E. The "Samia" of Menander. An interpretation of its plot and theme. Zeitschrift fur Papyrologie und Epigraphik. Bonn, 10, p. 1-20, 1973.

MENANDRI Reliquiae Selectae. SANDBACH, F. H. (ed.). Oxford: Oxford University Press, 1972.

MEANDRO. Commodie. Milano: Arnoldo Mondadori Editore, 1983.

POOLE, M. Menander's comic use of Euripides'tragedies. The Classical Bulletin. Saint Louis, Mo., 54, n.4, p. 56-62, 1978.

POST, CH. The dramatic art of Menander. Harvard Studies in Classical Philology. Cambridge, Mass., 24, p. 111-147, 1913.

SACONI, P. M. The plot on the Samia of Menander. The fault and the irony. Classica, São Paulo, 5/6: 111-116, 1992/1993.

ABSTRACT: The plot of the Samia by Menander -there being no initial real obstacle for the marriage of the young couple- is established by secondary problems which delay the denouement. The analysis of the existing relationships among the characters allows the identification of the composing structure and defines the intention of the poetic creation: the quest for Thruth as the theme. KEY WORDS: Menander, Samia, comedy, Greek Literature, Greece. 